\title{
Perancangan Sistem Jaringan Komputer Menggunakan Teknik Failover Pada Routing Static Yang Bersifat Recursive Connection
}

\author{
Budi Hartanto \\ Program Studi Teknik Informatika, STMIK Sinar Nusantara \\ filebudihartanto@gmail.com
}

\begin{abstract}
In a computer network system when using more than one router that is interconnected will experience a problem in the process of sending data packets. The problem is that if the main line is disconnected, then the data packet is unable to send data to a computer network system. The purpose of this study is to make a computer network system design with fail over technique on the type of static routing that is not directly connected. In this case the researcher used the Microtub Router Board RB-951-2nd. Failover technique is a way to transfer routing paths when the main line is broken, so it can be diverted to the backup routing path, this is so that the computer network connection path continues smoothly. The researcher used a recursive network connection case or the router is not connected directly to the main point center (main gateway), so the researcher used the optimization of the Target Scope and Distance features in the Microtic Router Board. The results of this study was that the backup routing path was able to channel data packets within the network if the main line did not respond or could not be connected.
\end{abstract}

Keywords: Computer Networks, Failover, Static Recursive Routing

\section{PENDAHULUAN}

Topologi jaringan komputer yang berada di SMK Muhammadiyah 2 Sukoharjo menggunakan 4 buah router, dimana masing-masing router saling terkoneksi dengan sistem recursive (tidak langsung ke router utama). Berdasarkan topologi tersebut maka akan muncul suatu kelemahan pada sistem jaringan yang ada di Sekolah tersebut. Kelemahan atau kendala yang akan muncul yaitu apabila salah satu koneksi ke router tersebut terputus atau tidak merespon, maka koneksi jaringan di Sekolah tersebut akan tidak terkoneksi ke jaringan internet. Failover merupakan suatu teknik yang dapat mengalihkan jalur koneksi routing utama ke jalur routing yang lainya, hal tersebut akan terjadi apabila jalur routing utama mengalami kegagalan atau terputus.

Penelitian ini dibuat untuk suatu perancangan jaringan dengan menggunakan teknik Failover pada jenis Routing Static. Teknik tersebut dapat mengatasi permasalahan yang nantinya akan muncul pada koneksi jaringan komputer di Sekolah tersebut. Penggunaan alat Router Board Mikrotik RB-951-2nd sebagai suatu media untuk melakukan optimalisasi terhadap kasus tersebut. Fitur yang digunakan untuk melakukan konfigurasi dalam teknik tersebut yaitu Distance dan Target Scope yang berada di dalam fitur router bard Mikrotik tersebut. Penelitian dengan menggunakan teknik akan akan mampu melakukan pengalihan jalur secara otomatis ke jalur yang lainya, apabila jalur routing yang utama mengalami masalah. Pengujian dilakukan terhadap jalur routing tersebut menggunakan fitur Trace Route, dengan menggunakan fitur ini nantinya akan terlihat gateway mana saja yang akan dilewati oleh paket data tersebut.

\section{TINJAUAN PUSTAKA}

2.1 Penelitian Sebelumnya

Judul penelitian Implementasi Failover Pada Jaringan WAN berbasis VPN, hasil dari penelitian tersebut menyatakan bahwa dengan menggunakan konfigurasi failover, yang 
dikontrol oleh mikrotik, pertukaran data dari kantor pusat ke kantor cabang lebih cepat dan jika terdapat gangguan salah satu koneksi jaringan internet terputus dapat dibackup oleh koneksi yang lain (Khasanah Siti Nur, 2018).

Hasil Penelitian yang dengan judul penelitian Implementasi Policy Base Routing dan Failover Menggunakan Router Mikrotik untuk Membagi Jalur Akses Internet di FMIPA Unnes, menyatakan bahwa berdasarkan hasil penelitian yang didapat maka dapat disimpulkan bahwa penggunaan policy base routing dapat memisahkan jalur akses pengguna ke internet dan dapat mempercepat akses ke sistem informasi di Unnes yang dibuktikan dengan hasil pengujian ping yang membutuhkan sedikit waktu respon dari yang sebelumnya yaitu dari sebelumnya yang membutuhkan waktu 4,6 ms hanya membutuhkan 1,6 ms atau menghasilkan peningkatan waktu respons sebesar $4 \mathrm{ms,}$ serta failover dapat berfungsi sebagai backup sehingga tidak terjadi kegagalan akses internet saat ISP utama terjadi gangguan (Ryo Pambudi, 2017).

\subsection{Topologi}

Pengertian topologi yaitu suatu layout atau arsitektur diagram jaringan komputer yang didalam mengandung rule atau aturan yang menghubungkan antara perangkat-perangat jaringan seperti work station, switch untuk saling bisa berkomunikasi (Sofana, 2014).

\subsection{Routing}

Merupakan suatu proses untuk meneruskan paket data didalam jaringan satu ke jaringan yang lainya sehingga akan terbentuk suatu jalur atau rute-rute tertentu didalam tabel routing (Hasanah F.U, 2014) .

\subsection{Failover}

Failover merupakan teknik yang dapat menerapkan beberapa rute untuk dapat mencapai suatu destination network. Akan tetapi dalam keadaan standar hanya ada satu link atau jalur yang digunakan. Link atau jalur yang lain akan berfungsi sebagai cadangan dan hanya akan digunakan apabila link utama telah terputus (Darmawan, 2017).

\subsection{Load Balance}

Pengertian Load Balance merupakan teknik yang digunakan untuk memisahkan antara beberapa link network. Dengan mempunyai banyak link maka dapat beban kerja , optimasi dari sumberdaya dan respon time akan semakin lebih baik. Load balancing dalam jaringan sangat penting bila skala dalam jaringan komputer makin besar demikian juga traffic data yang ada dalam jaringan komputer makin lama makin tinggi. Layanan Load balancing dimungkinkan pengaksesan sumber daya dalam jaringan didistribusikan ke beberapa host lainnya agar tidak terpusat sehingga unjuk kerja jaringan komputer secara keseluruhan bisa stabil. Beberapa kelebihan implementasi load balancing secara umum (Darmawan, 2017), yaitu

1. Waktu respon akses yang lebih cepat dibandingkan dengan pembagian jalur secara statik, ini dikarenakan beban dibagi ke dalam beberapa jalur sehingga beban pada masing-masing jalur menjadi lebih ringan.

2. Pengaturan untuk mencegah terjadinya penumpukan beban pada salah satu jalur, atau bisa dikatakan pemerataan pembebanan pada masing - masing jalur.

3. Dapat memisahkan dan mengatur jaringan nasional dan internasional agar tidak terjadi saling tarik menarik bandwidth pada jaringan sistem tersebut. 
4. Memperkecil kemungkinan terjadinya deadlock traffic yang sering kali terjadi pada perusahaan atau instansi.

\subsection{Redistribution}

Redistribution merupakan metode routing protokol yang digunakan sebagai sistem untuk meneruskan suatu routing protokol ke routing protokol yang lain agar dapat saling menukarkan routing table masing-masing. Metode redistribution ini adalah routing yang memiliki pemilihan jalur pengiriman yang berbeda dapat mengirimkan data satu sama lainnya. Hal ini akan membuat lebih mudah bagi network administrator untuk mengelola jaringan komputer yang dibutuhkan (Aryanto D, 2014). Teknik redistribution juga dapat diartikan sebagai solusi untuk melakukan komunikasi antar routing protocol redistribution adalah metode protokol routing yang digunakan untuk meneruskan suatu protokol routing ke protokol routing yang lain agar dapat saling menukarkan atau advertise routing table (Masykur, 2016).

\section{METODE PENELITIAN}

Metode yang digunakan dalam penelitian ini adalah metode eksperimental. Metode eksperimen termasuk dalam metode kuantitatif yang dilakukan di laboratorium dengan adanya perlakuan. Metode eksperimen dapat diartikan sebagai metode penelitian yang digunakan untuk mencari pengaruh perlakuan tertentu terhadap yang lain dalam kondisi yang terkendalikan. Metode eksperimen ini meliputi studi literatur, analisa, perancangan, implementasi dan pengujian sistem.

1. Studi Literatur Studi

Dalam langkah ini melibatkan pencarian dasar-dasar teori dan penelitian pendampingan yang telah dilakukan pada sebelumnya. Teori-teori yang terkait dengan permasalahan penelitian seperti, Mikrotik Router OS, dasar-dasar Load Balancing, Routing, Failover dan teori pendukung lain yang terkait dengan penelitian yang dilakukan oleh Penulis.

2. Analisa

Pada tahap analisa Peneliti melakukan beberapa hal yaitu melakukan analisa terhadap kebutuhan dan analisa proses yang digunakan dalam melakukan konfugurasi sistem Failover pada sistem jaringan tersebut. Pada tahapan analisa kebutuhan dibutuhkan mikrotik Router OS sebanyak 4, kabel UTP, Connector RJ-45, Modem ADSL dan Komputer yang digunakan untuk melakukan konfigurasi terhadap MikroTik Router OS tersebut.

3. Perancangan dan Implementasi

Tahapan perancangan dan Implementasi, dilakukan perancangan Topologi jaringan yang akan digunakan dalam konsep Failover tersebut. Pada tahapan Implementasi Peneliti melakukan konfigurasi Mikrotik Router OS tersebut menggunakan aplikasi Winbox. Konfigurasi yang dilakukan oleh Peneliti berlaku ke setiap router yang terhubung dalam sistem jaringan tersebut.

4. Pengujian

Dalam tahap pengujian hal yang dilakukan yaitu menguji atau melakukan pengecekan terhadap hasil konfigurasi sistem Failover pada sistem jaringan tersebut. Peneliti dalam tahapan ini menggunakan fitur Traceroute yang ada di dalam Mikrotik Router OS. Dalam pengujian ini menghasilkan laporan mengenai rute yang akan dilalui oleh paket data yang melakukan request ke jaringan publik atau internet. Laporan tersebut menghasilkan 2 perbandingan jalur rute paket data yang disebut dengan gateway, 
sehingga terdapat jalur utama untuk paket data dan jalur cadangan untuk menggantikan jalur utama apabila jalur utama tersebut terjadi kerusakan.

\section{HASIL DAN PEMBAHASAN}

Pada sistem jaringan komputer di SMK Muhammadiyah 2 Sukoharjo terdapat 4 buah router yang saling terbubung. Router tersebut terpasang di beberapa ruang atau gedung di Sekolah tersebut. Adapun topologi jaringan di Sekolah tersebut seperti pada Gambar 1.

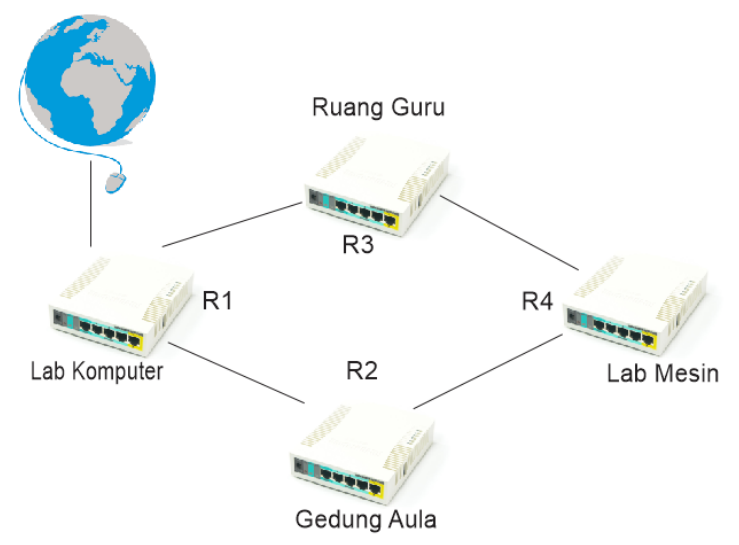

Gambar 1 Topologi Jaringan SMK Muhammadiyah 2 Sukoharjo

Terdapat 4 router yang saling terhubung dalam sistem jaringan di SMK Muhammadiyah 2 Sukoharjo. Router 1 berperan sebagai router induk yang mensuplai akses internet ke router 2 , router 3 dan router 4. Sehingga dengan topologi tersebut maka dapat diberlakukan konfigurasi failover. Adapu konfigurasinya adalah sebagai berikut.

\subsection{Konfigurasi IP Address}

\section{Pada Router -1}

Pada Gambar 2 tersebut merupakan konfigurasi IP Address dari router 1. terlihat terdapat tiga buah interface yang digunakan. ether1 terhubung ke internet ether2 terhubung ke router 2 dan ether3 terhubung ke router 3.

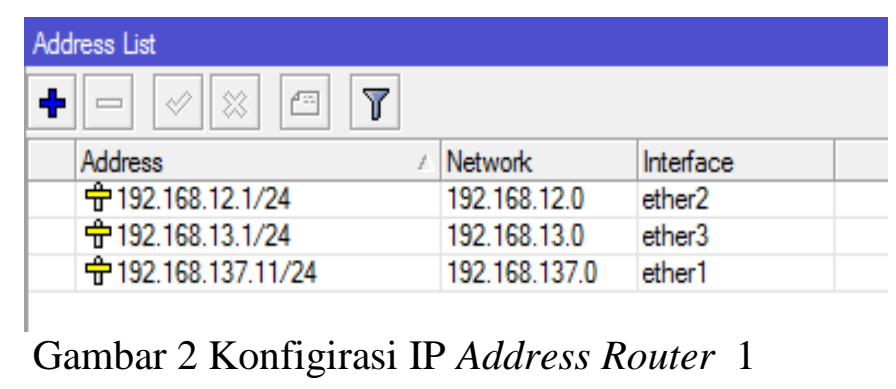

\section{Pada Router -2}

Pada Gambar 3 tersebut merupakan konfigurasi IP Address dari router 2. terlihat terdapat dua buah interface yang digunakan. ether1 terhubung ke router 1 dan ether2 terhubung ke router 4. 


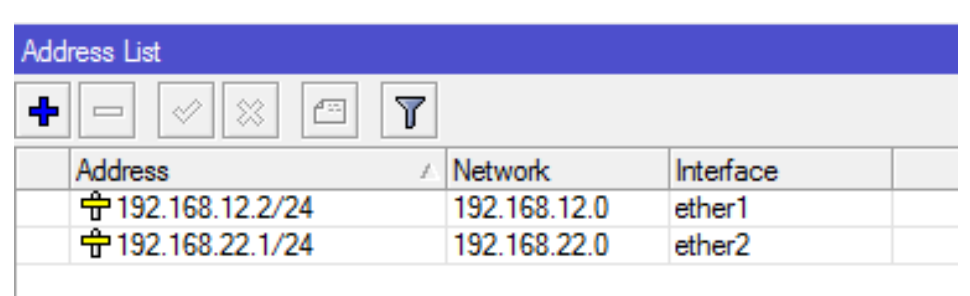

Gambar 3 Konfigirasi IP Address Router 2

Pada Router -3

Pada Gambar 4 tersebut merupakan konfigurasi IP Address dari router 3. terlihat terdapat dua buah interface yang digunakan. ether1 terhubung ke router 1 dan ether2 terhubung ke router 4.

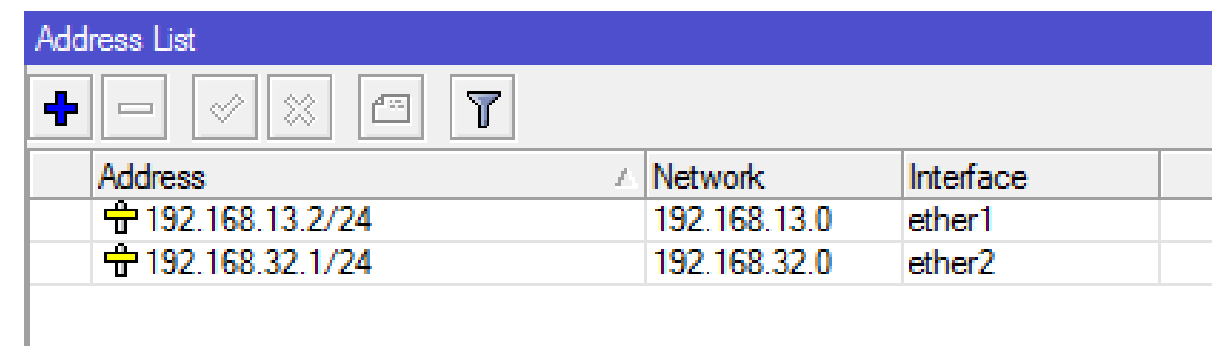

Gambar 4 Konfigirasi IP Address Router 3

Pada Router -4

Pada Gambar 5 tersebut merupakan konfigurasi IP Address dari router 2. terlihat terdapat dua buah interface yang digunakan. ether1 terhubung ke router 1 dan ether2 terhubung ke router 4.

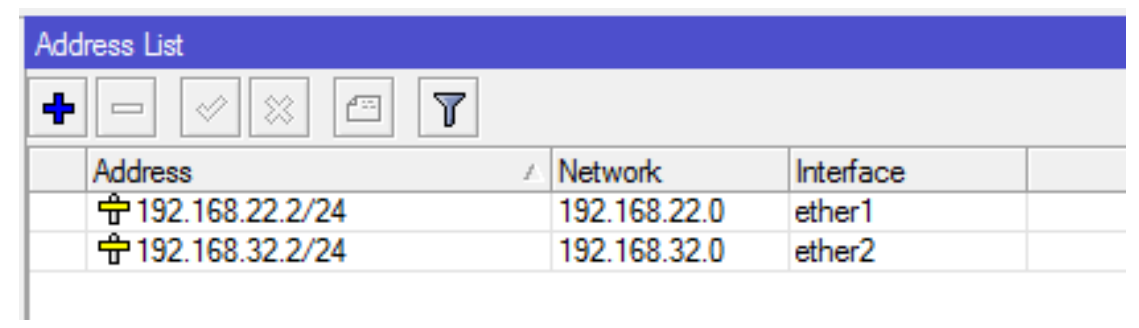

Gambar 5 Konfigirasi IP Address Router 4

\subsection{Konfigurasi Failover}

Pada konfigurasi Failover seperti pada Gambar 6 dan Gambar 7, pengisian alamat gateway sebanyak 5 jalur, hal tersebut bertujuan untuk membat sistem pencadangan terhadap jalur utama, sehingga apabila nantinya jalur utama mengalami kendala, maka jalur cadangan akan otomatis melakukan pengalihan jalur pada paket data tersebut. 


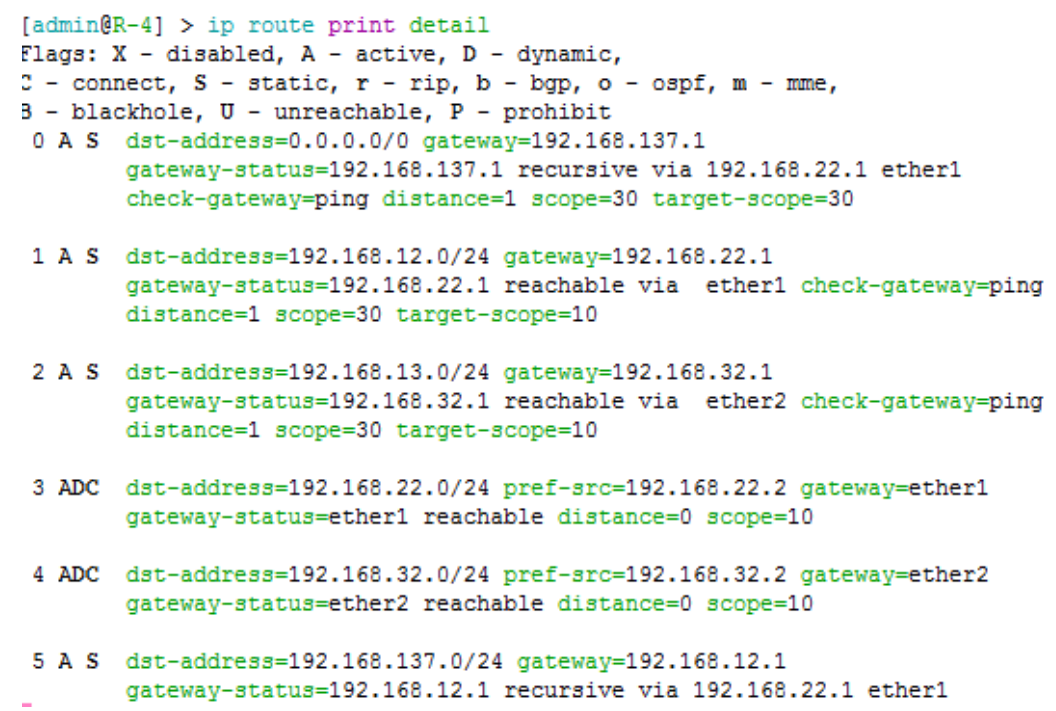

\section{Gambar 6 Konfigurasi Failover Pada Router 4 CLI}

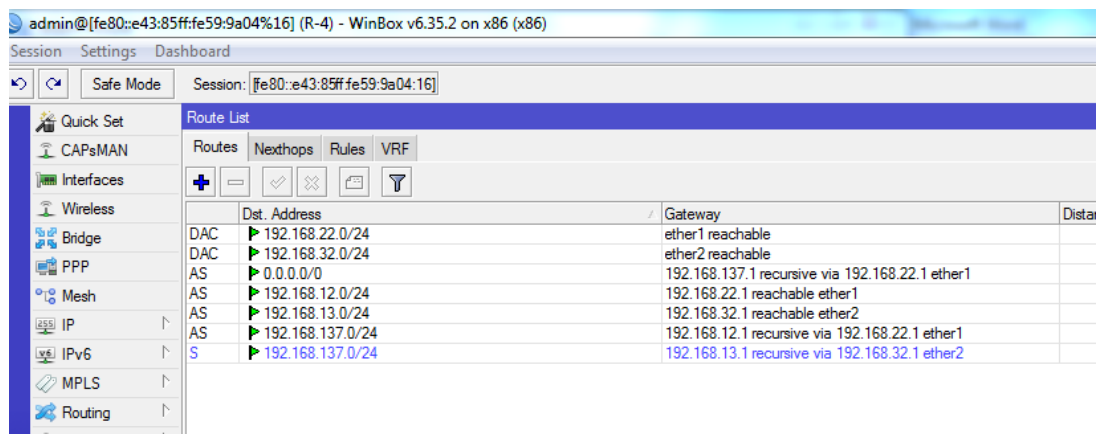

Gambar 7 Konfigurasi Fai over Pada Router 4 GUI

\subsection{Pengujian}

\section{Pengujian Jalur Router Utama}

Dari hasil pengujian jalur paket data yang telah dibuat, terlihat apabila melakukan akses paket data ke internet, maka jalur yang akan dilalui melewati router -2 dengan urutan 192.168.22.1 kemudian 192.168.12.1 berikutnya 192.168.137.1, selanjutnya mengarah kejalur internet atau publik. Pengujian pertama jalur utama seperti pada Gambar 8, pengujian kedua jalur seperti pada Gambar 9 dan pengujian jalur ketiga seperti pada Gambar 10.

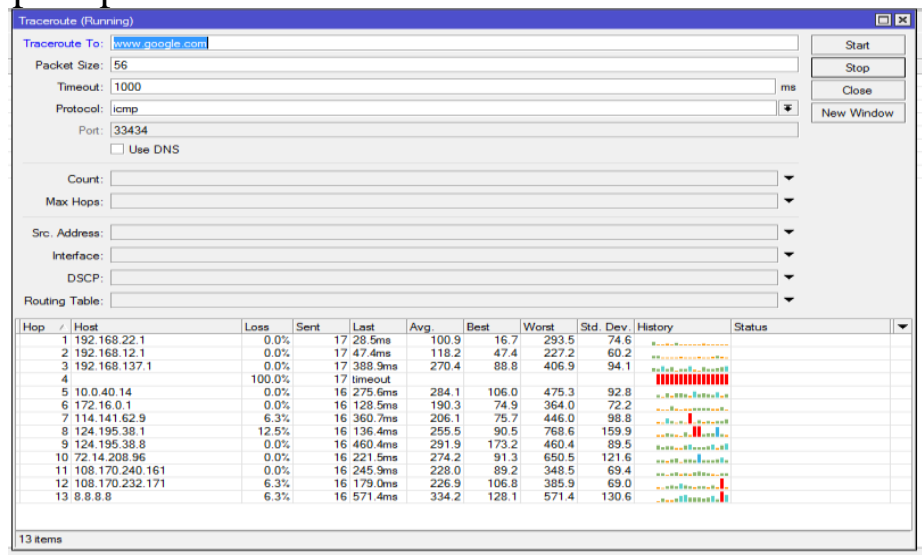

Gambar 8 Pengujian Pertama Jalur Utama 


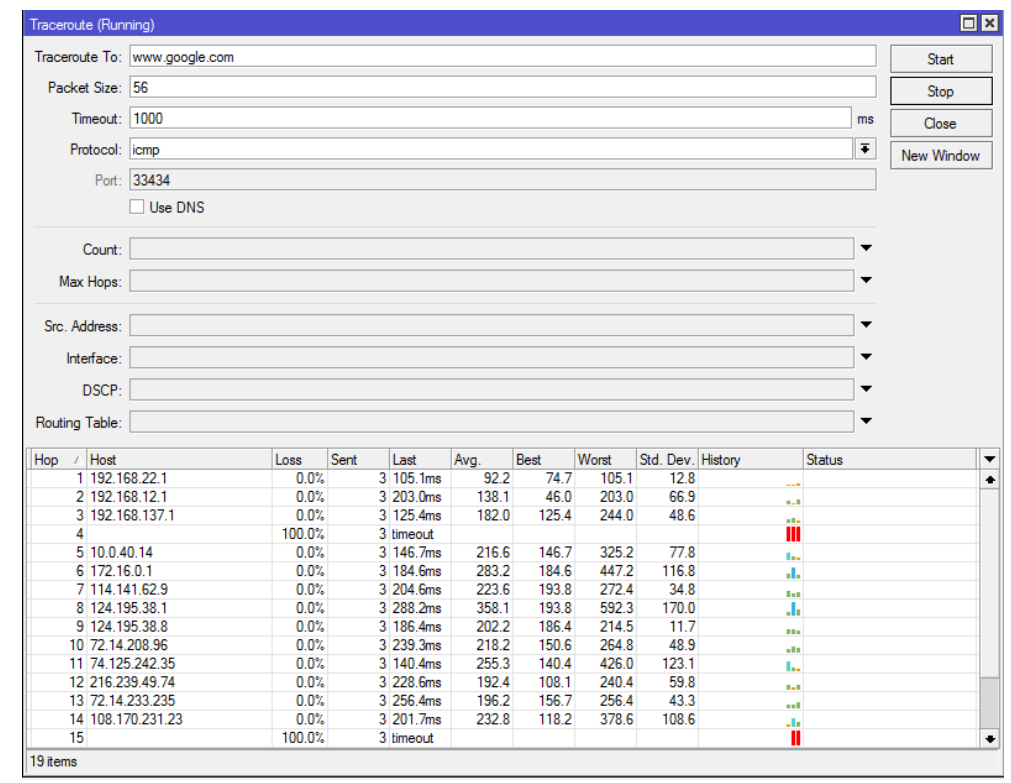

Gambar 9 Pengujian Kedua Jalur Utama

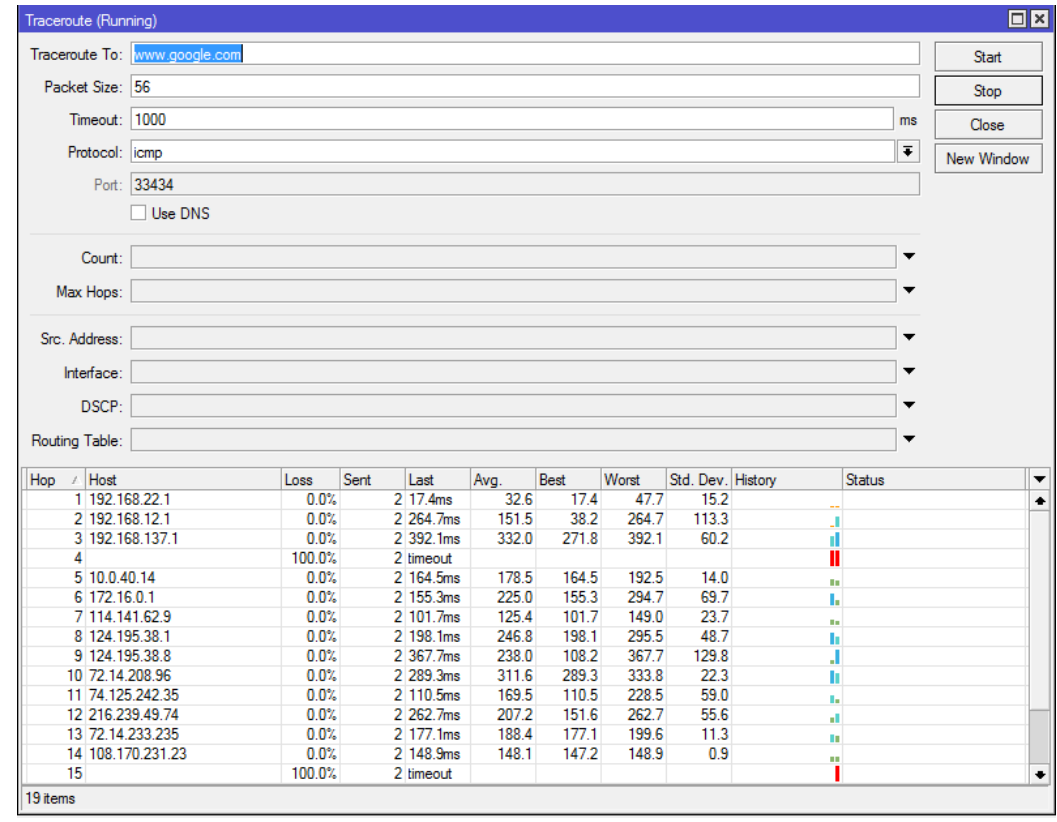

Gambar 10 Pengujian Ketiga Jalur Utama

2. Pengujian Jalur Router Cadangan

Apabila jalur utama mengalami kerusakan atau mengalami trafik pelayanan pengiriman paket data terlalu tinggi, maka jalur cadangan ini secara otomatis akan melakukan pengalihan dari jalur utama menuju ke jalur cadangan tersebut, atau secara lebih detail dari gateway 192.168.22.1 menuju ke 192.168.32.1, kemudian menuju ke jaringan internet atau jaringan publik. Gambar 11 merupakan tampilan ketika jalur utama mengalami kerusakan atau terputus. 


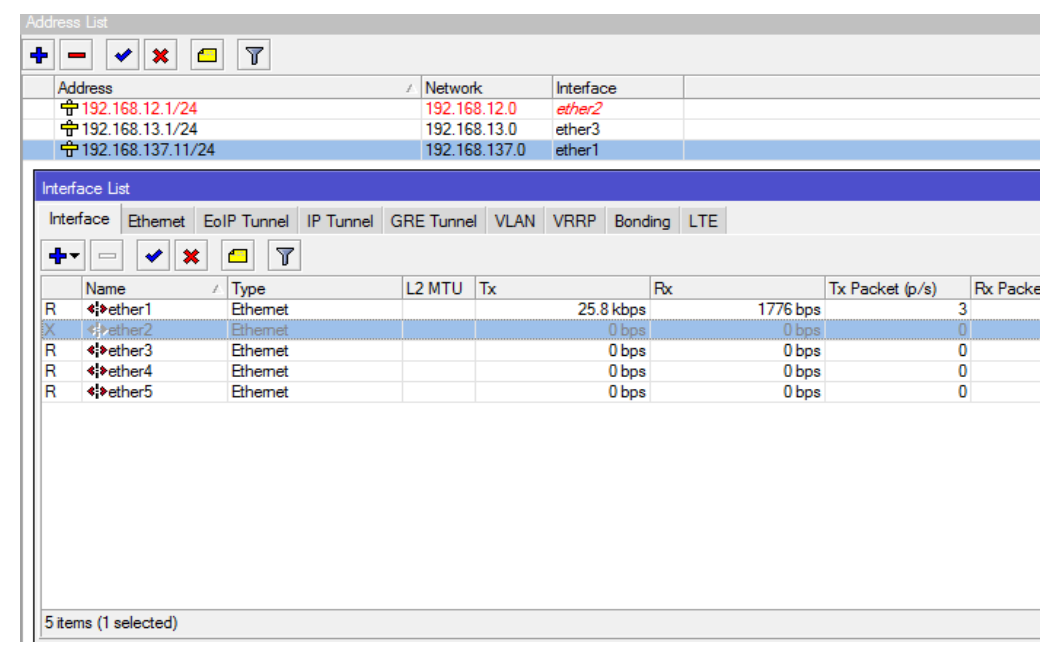

Gambar 11. Jalur Utama Pada Router 2 (Ruang Aula) Terputus.

Apabila dilakukan pengujian tehadap jalur tersebut, maka akan terjadi keterlambatan dalam proses penyampaian paket data, akan tetapi dalam beberapa waktu jalur cadangan akan menjalankan fungsi untuk melakukan penyampaian paket data. Tampilan dari proses migrasi jalur apabila terjadi kerusakan pada jalur utama seperti pada Gambar 12, Gambar 13 dan Gambar 14.

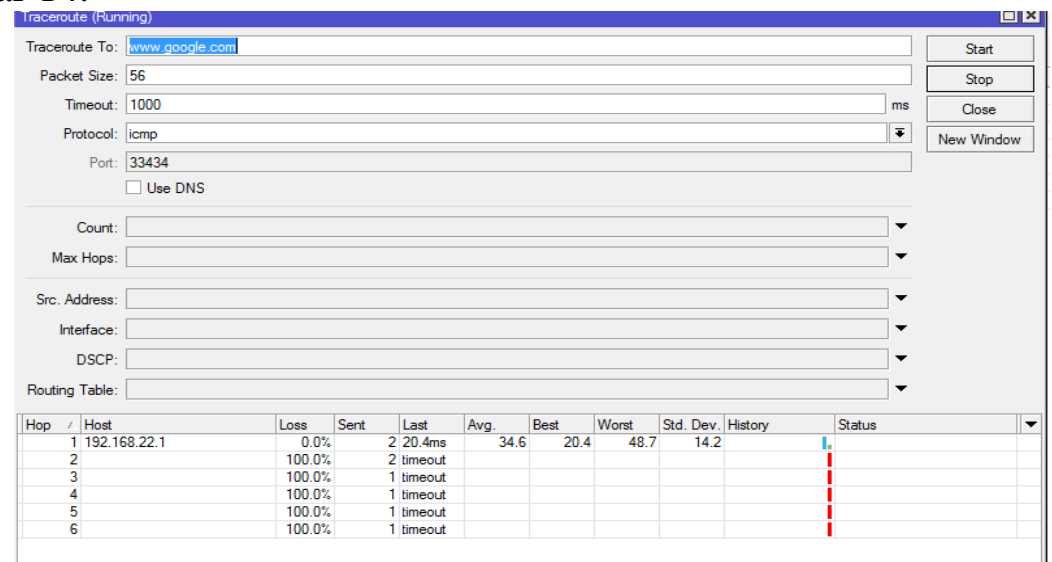

Gambar 12. Pengujian Keempat Jalur Utama yang terputus

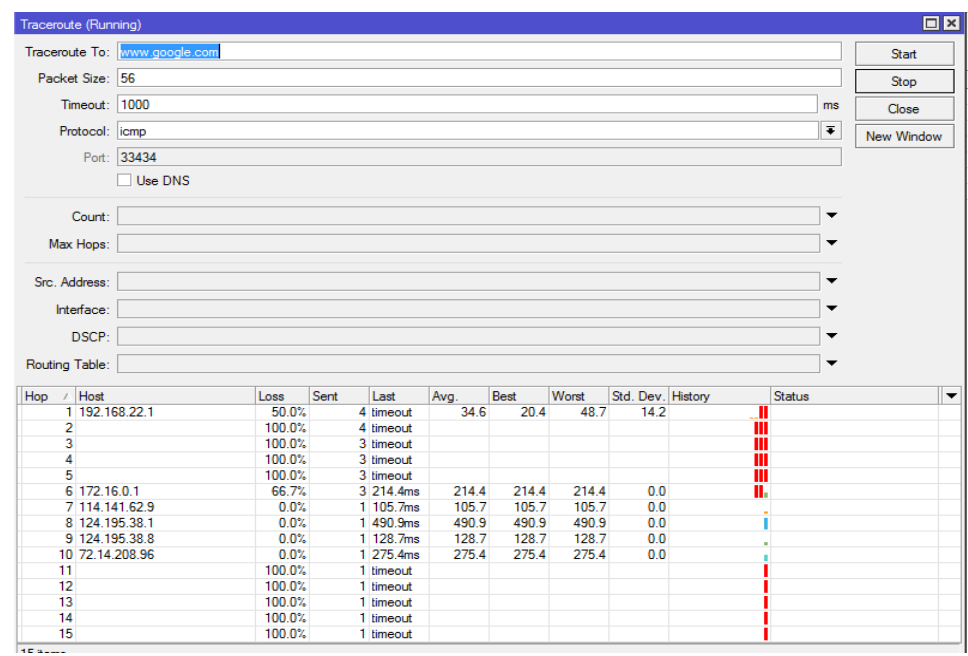

Gambar 13. Pengujain Kelima (Cadangan Mulai Melakukan Migrasi Paket Data) 


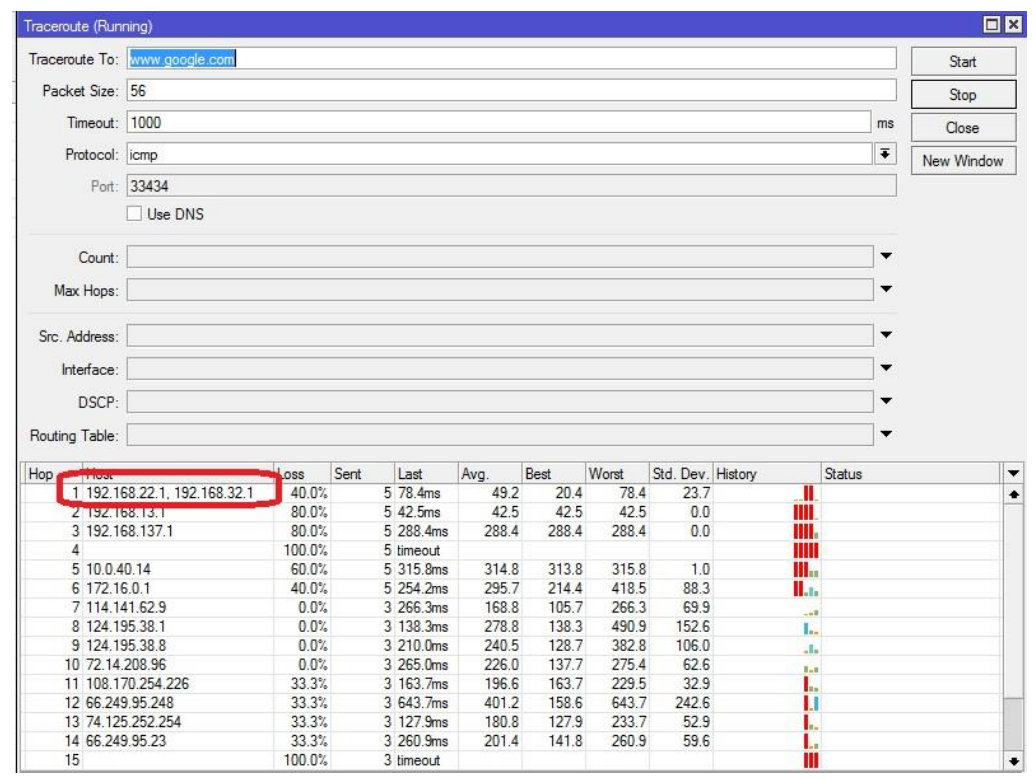

Gambar 14. Perpindahan Jalur Utama ke Jalur Cadangan

Berdasarkan uraian dan hasil dari pengujian tersebut, maka teknik failover atau perpindahan jalur utama ke jalur cadangan berhasil dilakukan. Pengujian tersebut dibuktikan dari tampilan Gambar 11 yang menampilkan jalur utama terputus, Gambar 12 merupakan pengujian jalur utama yang tidak merespon pengguna untuk menyampaikan paket data, Gambar 13 yaitu mulai terjadi migrasi paket data dan Gambar 14 yang menampilkan terjadi perpindahan jalur utama yaitu IP Address 192.168.22.1 ke IP Address 192.168.32.1. Hasil pengujian dari teknik failover di SMK Muhammadiyah 2 Sukoharjo seperti pada Tabel 1.

Tabel 1 Hasil Percobaan Pengujian Jalur

\begin{tabular}{|c|l|l|c|}
\hline No & Pengujian Jalur Utama & \multicolumn{1}{|c|}{ Hasil Koneksi } & Lama Hop ke Public \\
\hline 1 & Pengujian pertama & Tersambung & $274 \mathrm{~ms}$ \\
\hline 2 & Pengujian kedua & Tersambung & $218 \mathrm{~ms}$ \\
\hline 3 & Pengujian ketiga & Tersambung & $289 \mathrm{~ms}$ \\
\hline 4 & Pengujian keempat & Terputus & timeout \\
\hline 5 & Pengujian Kelima & Tersambung & $226 \mathrm{~ms}$ \\
\hline
\end{tabular}

Terlihat dari pengujian pertama, jalur utama masih tersambung dengan lama waktu untuk mencapai titip hop ke jaringan public $274 \mathrm{~ms}$. Pengujian kedua tersambung dengan waktu untuk ke jaringan publik $218 \mathrm{~ms}$. Berikutnya pengujian ketiga tersambung dengan membutuhkan waktu 289 ms. Pada pengujian keempat jalur utama terputus, kemudian terlihat pada pengujian kelima jalur cadangan mulai menggantikan peranan dari jalur utama dengan membutuhkan waktu 226 ms untuk mencapai ke titik hop jaringan publik.

\section{KESIMPULAN DAN SARAN}

\subsection{Kesimpulan}

Peneliti dalam sub bab ini melakukan penarikan kesimpulan dari penelitian mengenai konfigurasi Failover Routing Static yang bersifat recursive. Adapun kesimpulan yang dapat dipaparkan dalam penelitian ini yaitu. 
1. Dengan menggunakan teknik failover recursive pada sistem jaringan koneksi jaringan komputer di SMK Muhammadiyah 2 Sukoharjo, apabila pada jalur utama terjadi kerusakan, maka jalur cadangan dapat menggantikan peranan jalur utama untuk menyampaikan paket data.

2. Berdasarkan hasil pengujian yang telah dilakukan lima kali percobaan, didapatkan hasil bahwa waktu yang dibutuhkan untuk menuju ke titik hop jaringan public berbeda-beda. Pada pengujian pertama hingga ketiga jalur utama mampu menyampaikan paket data. Pada pengujian keempat terjadi kerusakan jalur utama. Pada pengujian kelima jalur cadangan dapat melakukan migrasi paket data dari jalur utama yang sedang mengalami kerusakan.

3. Konfigurasi routing menggunakan target scope yang bersifat recursive, hal tersebut dapat membantu pembuatan jalur paket data terhadap Router yang tidak langsung terhubung ke Gateway yang paling awal.

4. Terdapat 2 jalur yang akan digunakan oleh paket data untuk melakukan pengiriman paket data ke internet, yaitu jalur Utama dengan gateway 192.168.22.1 dan jalur cadangan dengan gateway 192,168.32.1. Semua jalur tersebut dikonfigurasi dengan Teknik Routing Statis.

\subsection{Saran}

Untuk membangun sistem failover yang lebih baik, maka dalam hal ini disarankan agar kedepan selain menggunakan teknik failover dengan Routing Statis, sebaiknya juga menggunakan teknik failover dengan Routing Dinamis. Teknik Routing Dinamis tersebut dapat dibuat dengan Metode Routing Informations Protocol (RIP) atau dapat menggunakan Open Short Path First (OSPF). Hal tersebut bertujuan agar mendapatkan hasil perbandingan antara Routing Statis atau Routing Dinamis, sehingga dapat diambil sisi kelebihan dan kekurangan dari masing-masing jenis teknik routing tersebut.

\section{DAFTAR PUSTAKA}

Aryanto D, P. (2014). Perancangan dan Analisis Reditribution Routing OSPF dan EIGRP. Elkomika, 85-89.

Darmawan, I. T. (2017). Analisa Link Balancing dan Failover 2 Provider Menggunakan Border Gateway Protocol Pada Router Cisco 7606s. Jurnal Nasional Teknologi Dan Sistem Informasi , 326-333.

Hasanah F.U, M. (2014). Analisis Kinerja Routing Dengan Teknik RIP Pada Topologi Ring dalam Jaringan LAN menggunakan Packet Tracer. Singuda Ensikom, 118124.

Khasanah Siti Nur, U. L. (2018). Implementasi Failover Pada Jaringan WAN. Jurnal Teknik Informatika , 62-66.

Masykur. (2016). Penggabungan Routing Protocol dengan Redistribution. In SNATIF , 3942.

Ryo Pambudi, M. A. (2017). Implementasi Policy Base Routing dan Failover Menggunakan Router . Jurnal Teknologi dan Sistem Komputer, , 57-61.

Sofana, I. (2014). Ciscon CCNA \& Jaringan Komputer. Bandung: Informatika. 